\title{
Research Paper \\ Demographic, Clinical, and Radiological Characteristics of Patients With Hydatid Cyst Refereed to Ahvaz Hospitals During 2017-2019
}

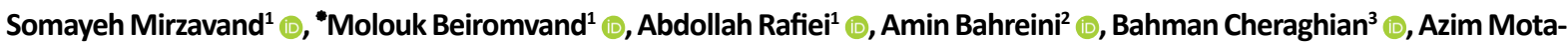 \\ medfar $^{4}\left(\mathbb{B}\right.$, Abdolhadi Jahanshahi $^{2}$ (1)
}

1. Department of Parasitology, School of Medicine, Ahvaz Jundishapur University of Medical Sciences, Ahvaz, Iran.

2. Department of Surgery, School of Medicine, Ahvaz Jundishapur University of Medical Sciences, Ahvaz, Iran.

3. Department of Biostatistics and Epidemiology, School of Health, Ahvaz Jundishapur University of Medical Science, Ahvaz, Iran.

4. Department of Radiology, School of Medicine, Ahvaz Jundishapur University of Medical Sciences, Ahvaz, Iran.

$\begin{gathered}\text { Use your device to scan } \\ \text { and read the article online }\end{gathered}$
Citation Mirzavand S, Beiromvand M, Rafiei A, Bahreini A, Cheraghian B, Motamedfar A, et al. [Demographic, Clinical, and Radio-
logical Characteristics of Patients With Hydatid Cyst Refereed to Ahvaz Hospitals During 2017-2019 (Persian)]. Jundishapur Journal of
Medical Sciences. 2021; 20(5):486-497. https://doi.org/10.32598/JSMJ.20.5.2516
dol'https://doi.org/10.32598/JSMJ.20.5.2516

Received: 08 Aug 2021 Accepted: 01 Oct 2021 Available Online: 01 Dec 2021

Keywords: Hydatid cyst, Echinococcus granulosus, Hydatidosis, Ahvaz, Iran

\section{A B STRACT}

Background and Objectives Hydatid cyst is a worldwide zoonotic disease caused by the larval stages of Echinococcus granulosus. The aim of this study was to investigate the demographic, clinical and radiological characteristics of hydatidosis patients undergoing surgery in hospitals in Ahvaz during

Subjects and Methods This study is a retrospective descriptive cross-sectional study based on the information recorded in the patients' files. Data were analyzed using SPSS software, descriptive statistics and Chi-square test.

Results Of the 107 patients with a mean age of 36.78 years, $42.1 \%$ were male and $57.9 \%$ were female. The highest frequency was related to the age group of 31-40 and the lowest was related to the patients under 10 years old. $52.3 \%$ lived in the rural areas and $47.7 \%$ lived in the urban areas. In $70.1 \%$ of the patients, liver was involved and recurrence was reported in $14 \%$. In $59.8 \%$ of the patients, only one cyst was reported and in $40.2 \%$ more than one cyst was reported. The cysts size was 10 to $180 \mathrm{~mm}$ and about $50 \%$ of the patients had CE2 cysts. The diagnostic method of all patients was imaging techniques and drainage method was the most common method used.

Conclusion This study showed that hydatid cyst in Khuzestan Province is still one of the important health problems that raise the need for educational programs based on the prevention and control of parasitic infections, especially parasites transmitted by dogs. Observation of $14 \%$ recurrence also raises the importance of choosing the appropriate surgical method by surgeons.

\section{* Corresponding Author: \\ Molouk Beiromvand, PhD.}

Address: Department of Parasitology, School of Medicine, Ahvaz Jundishapur University of Medical Sciences, Ahvaz, Iran

Tel: +98 (916) 3445838

E-Mail: beiromvandm@gmail.com 


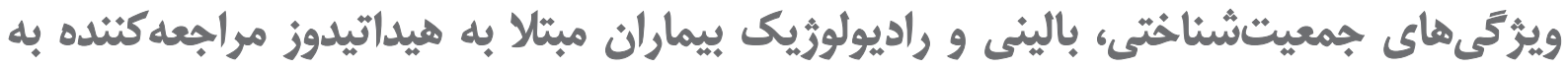

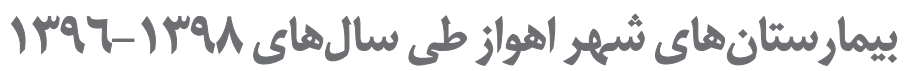

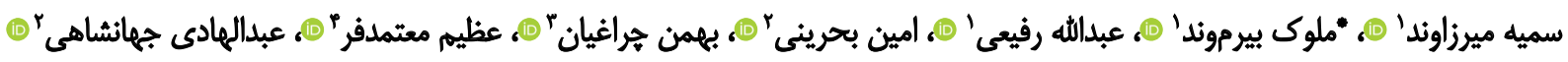

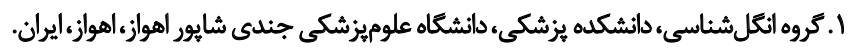

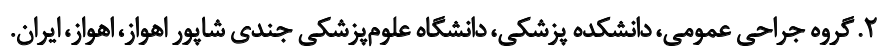

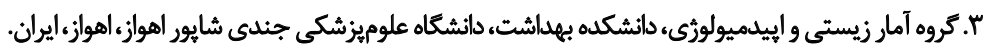

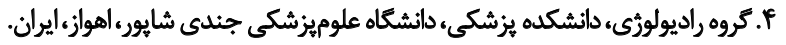

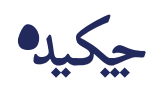

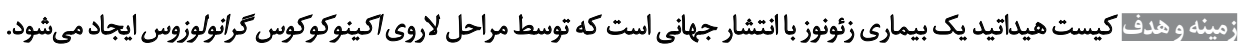

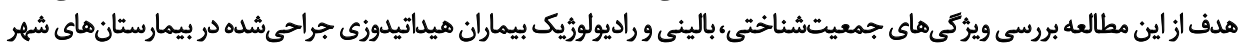

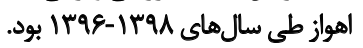

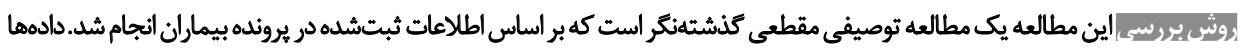

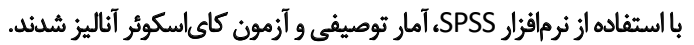

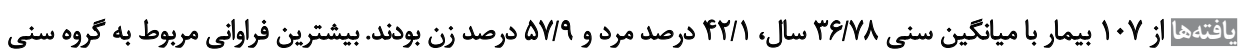

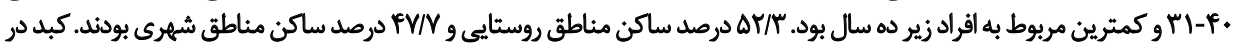

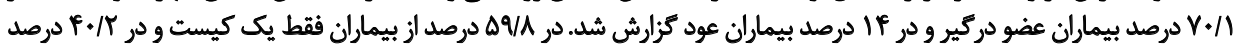

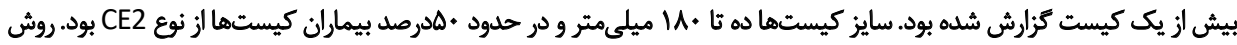

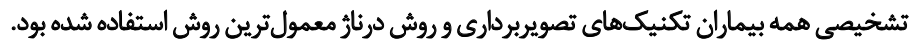

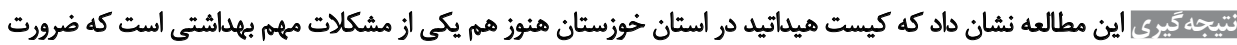

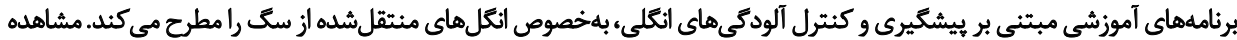

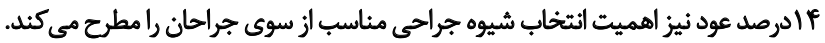

$$
\begin{aligned}
& \text { تاريخ دريافت: IV مرداد . IF }
\end{aligned}
$$

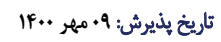

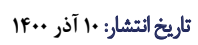

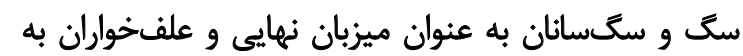

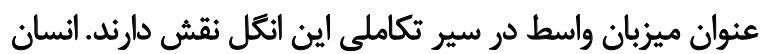

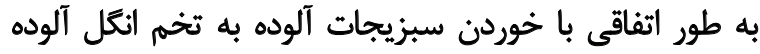

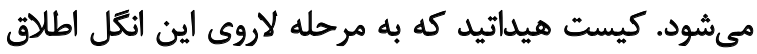

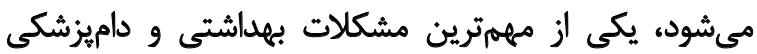

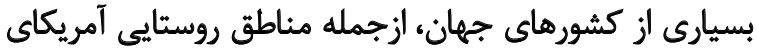

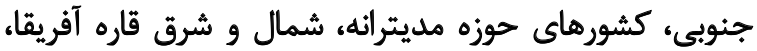

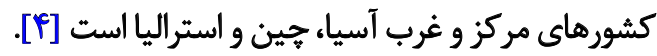

سيستيك اكينوكوكوزيس' يك عفونت زئونوز مهم است كه به به

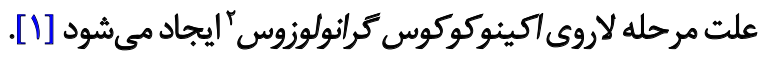

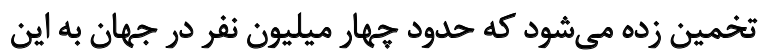

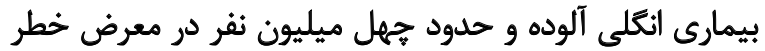

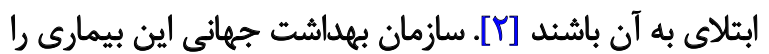

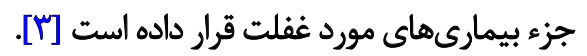

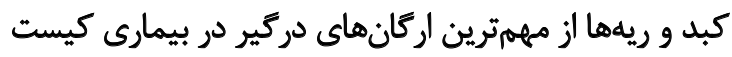

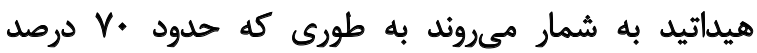

1. Cystic Echinococcosis

2. Echinococcus Granulosus

-

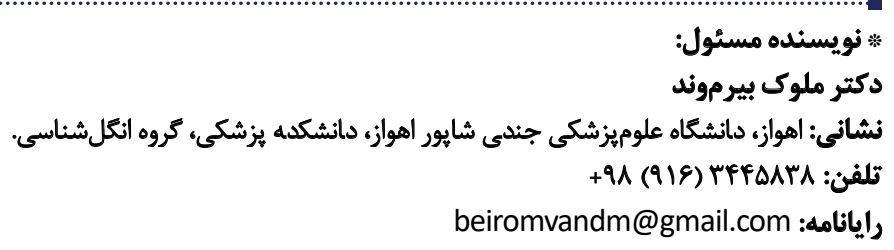




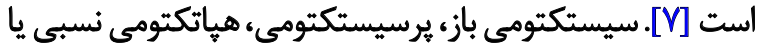

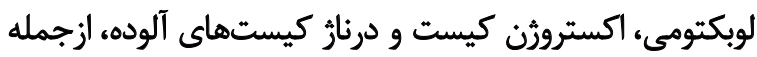

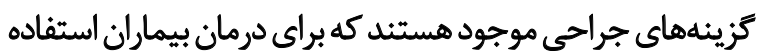
مىشود [· [1]. ايران، يكى از مهمترين مناطق اندميك كيست هيداتيد در

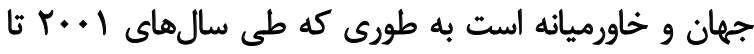

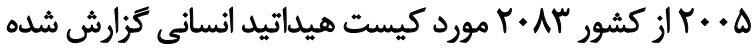

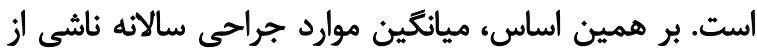

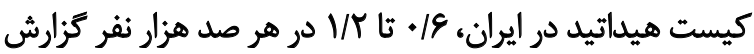

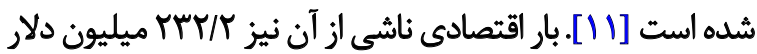
تخمين زده شده است [IIT].

عليرغم اينكه استان خهوزستان، ازجمله مناطق اندميك مئيك

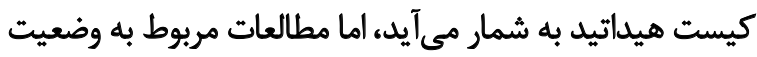

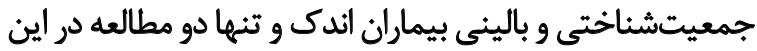

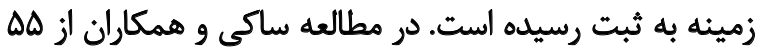

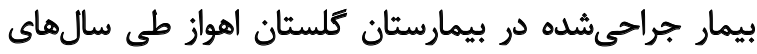

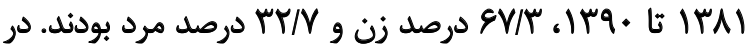

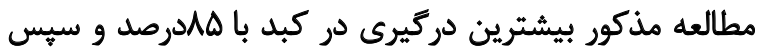

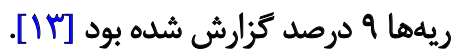

همجنين در مطالعه يديد و همكاران از MA بيمار جراحىشده

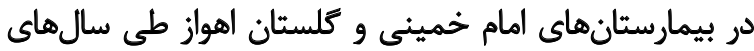

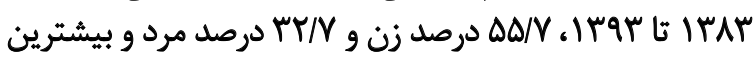

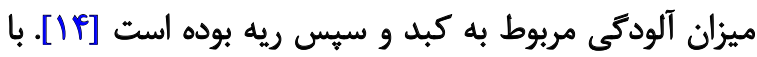

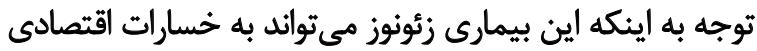

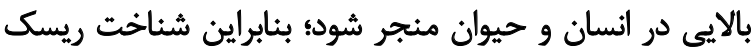

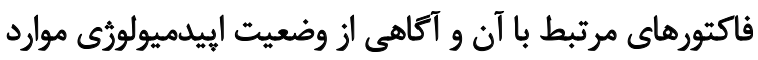

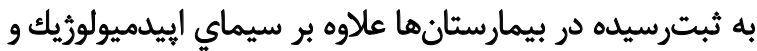

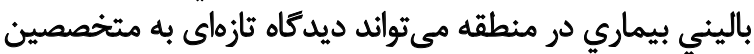

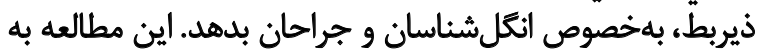

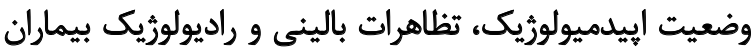

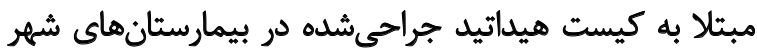

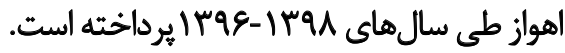

\section{روش بروسي}

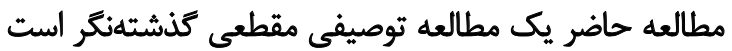

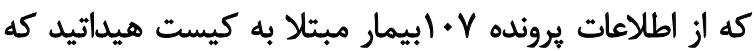

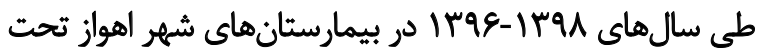

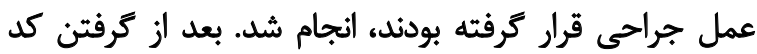

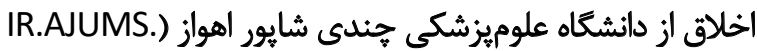

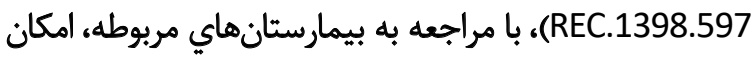

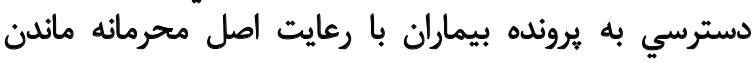

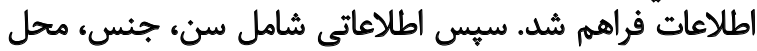

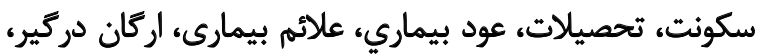

موارد مربوط به كبد، · ب درصد ريهها و مابقى مربوط به ساير باير

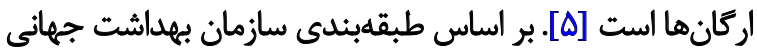

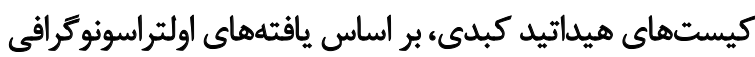

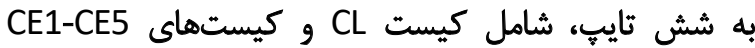

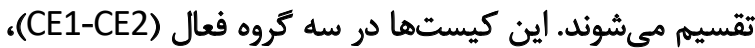

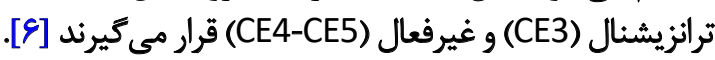
كيستهاى نوع CL تك حفرهاي، همورثن، بدون اكورئسيته و

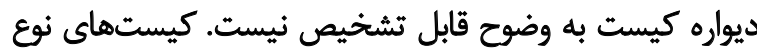
تك CE1

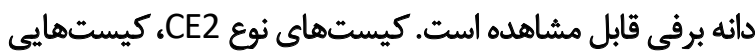

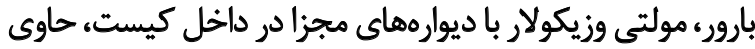

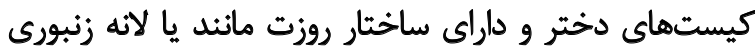

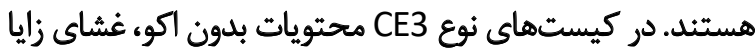

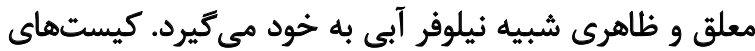

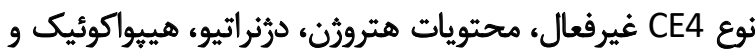

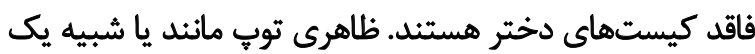

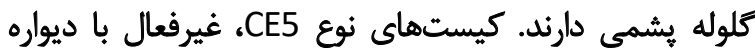

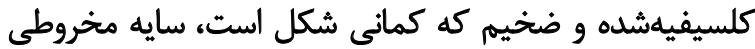

شكل ايجاد مى كنيند [8].

تظاهرات بالينى كيست هيداتيد، بسته به محل كيست، اندازه

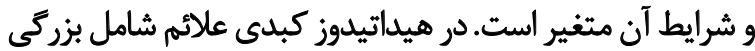

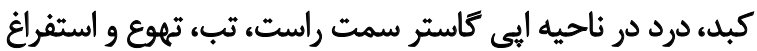

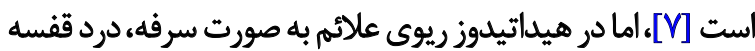

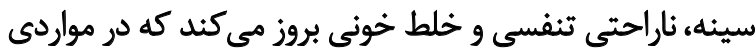

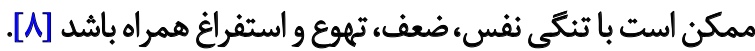
تشخيص كيست هيداتيد بر اساس تاريخجه بيماري، معاينه

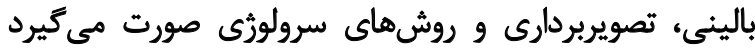

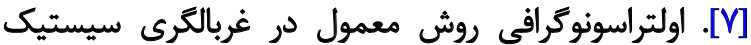

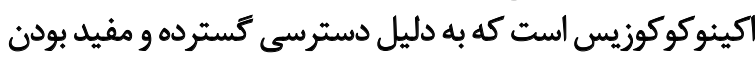
آن براى تعيين تعداد، محل، ابعاد، بارور و فعال بوديت بودين كيست

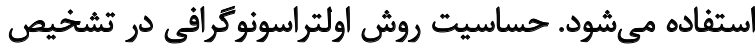

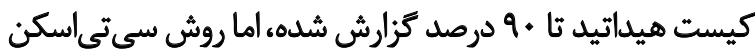

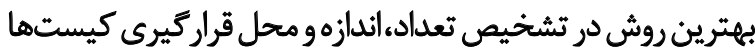
با حساسيت •. 1 إدرصد است.

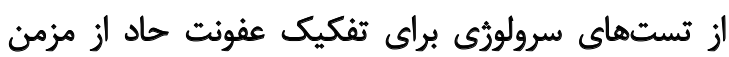

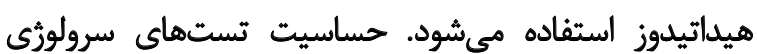

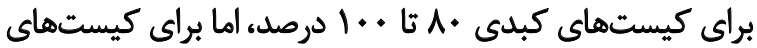

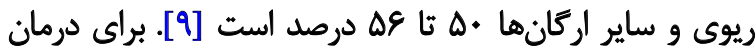

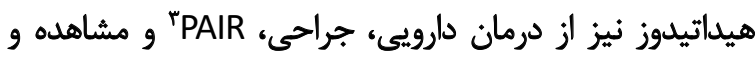

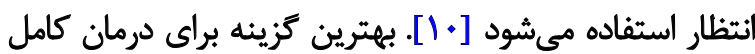
و فورى هيداتيدوز، خارج كردن كامل كيست طي عمل جرين براحي درمان كامل

\section{Puncture, Aspiration, Injection and Reaspiration}


كبدى، روش درناز با ل VT// درصد معمول ترين روش استفادهده

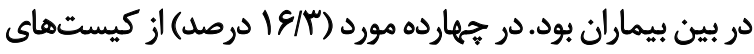

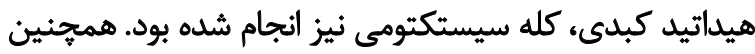

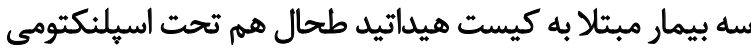

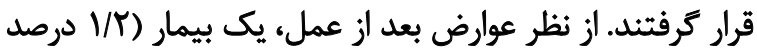

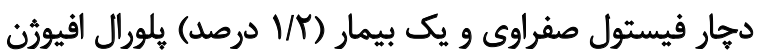

شد (جدول شماره بَ).

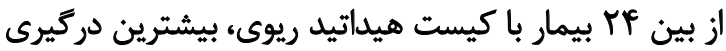

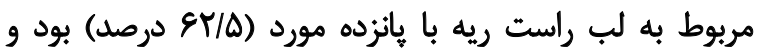

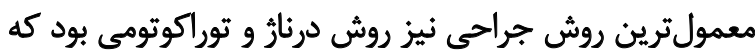

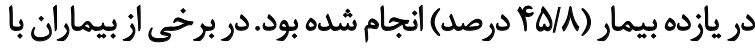

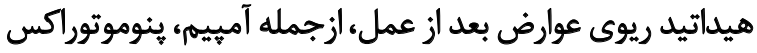

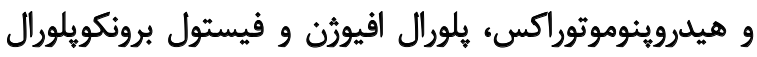
كزارش شده بود (جدول شماره f).

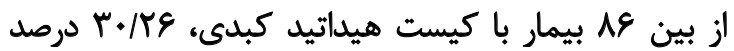

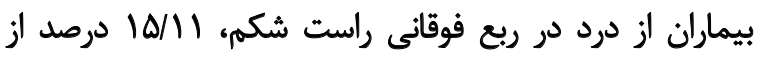

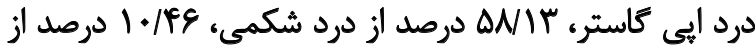

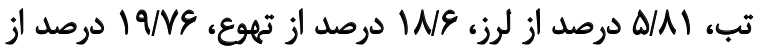

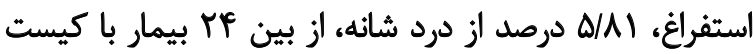

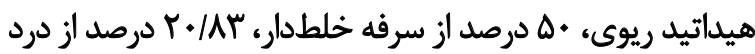

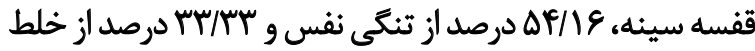
خونى شكايت داشتند (جدول شماره ه). روش هاى تشخيصى مورد استفاده در عم مورد كيست هيداتيد

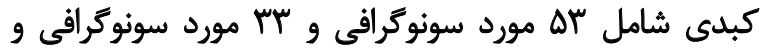

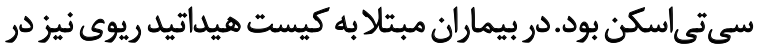

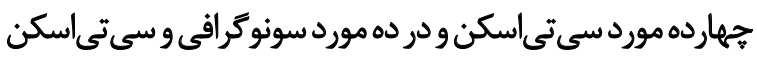

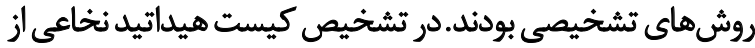

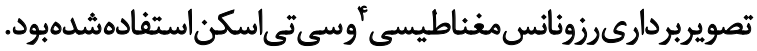

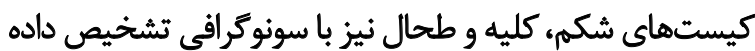

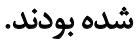

ث

كيست هيداتيد يك بيمارى انظلى زئونوز با انتشار جهانى است

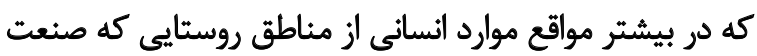

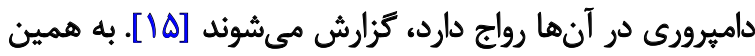

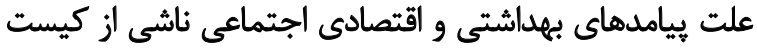

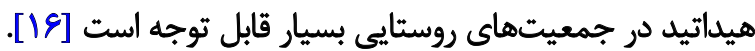

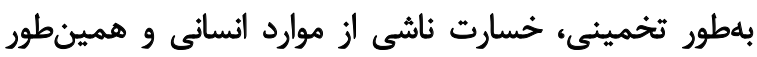

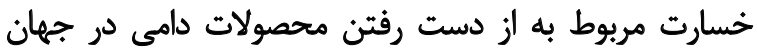

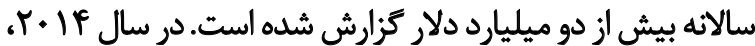

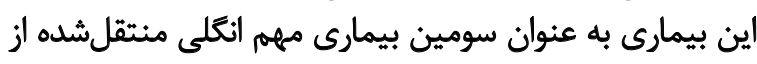

\section{Magnetic Resonance Imaging}

تعداد كيست در هر بيمار، اندازه كيستها، لوب دركير، نتيجه

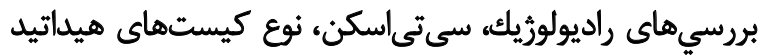

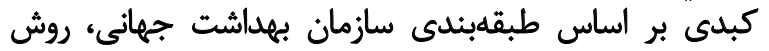
جراحى و عوارض يس از عمل جمع آورى شدان بهان.

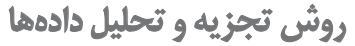

جهت توصيف دادهها از ميانكين و انحراف معيار براي

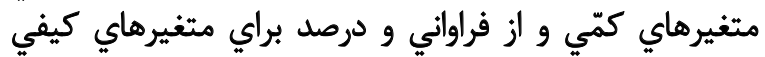

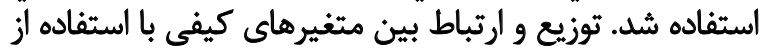

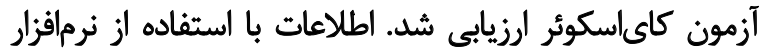
نسخه FPSS

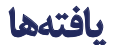

به طور كلى از V| ا بيمار مبتلا به كيست هيداتيد كه طى إنى

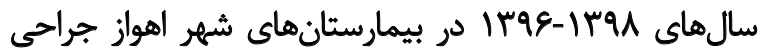

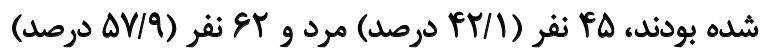

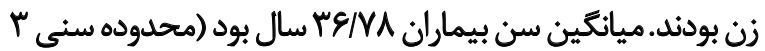

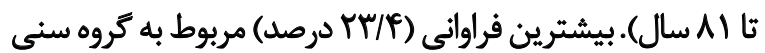

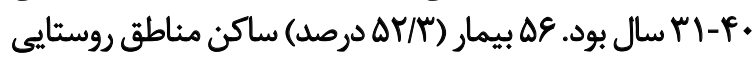
و اله بيمار fVV/V) درصد ساكن مناطق شهرى بودند.

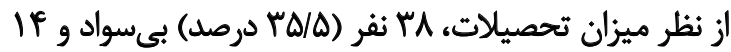

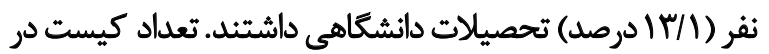

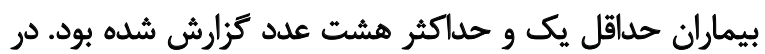

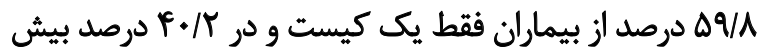

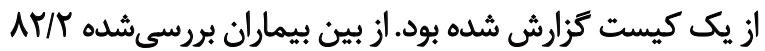

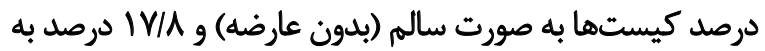

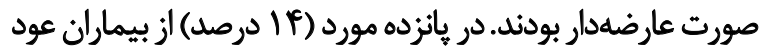

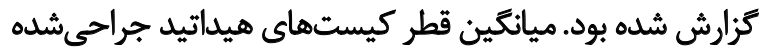

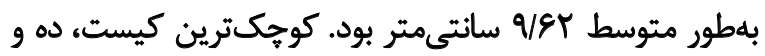
بزركترين كيست • 11 ميلىمتر بود (جدول شماره ()).

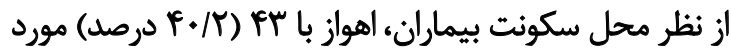

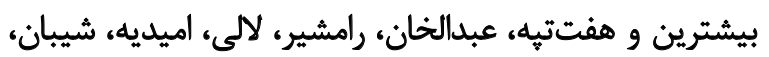

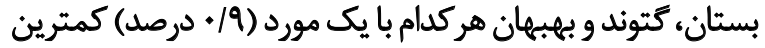

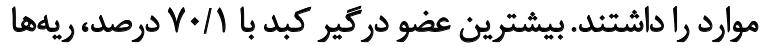

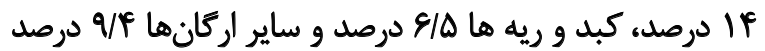

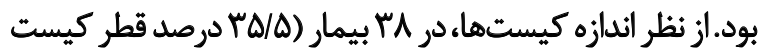

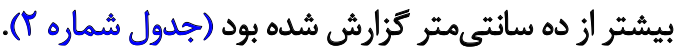

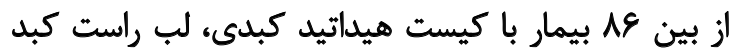

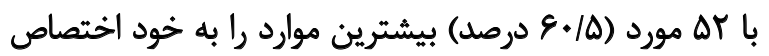

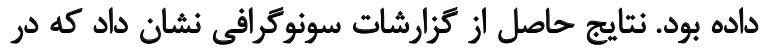

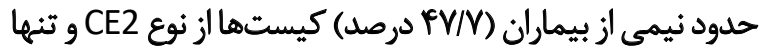

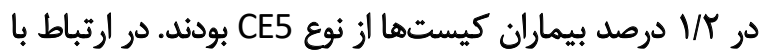

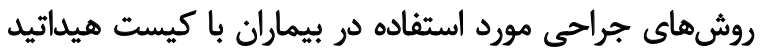




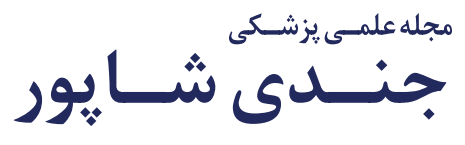

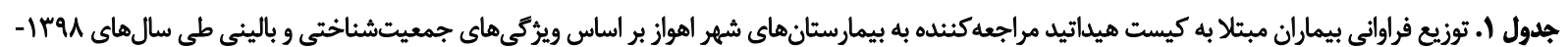

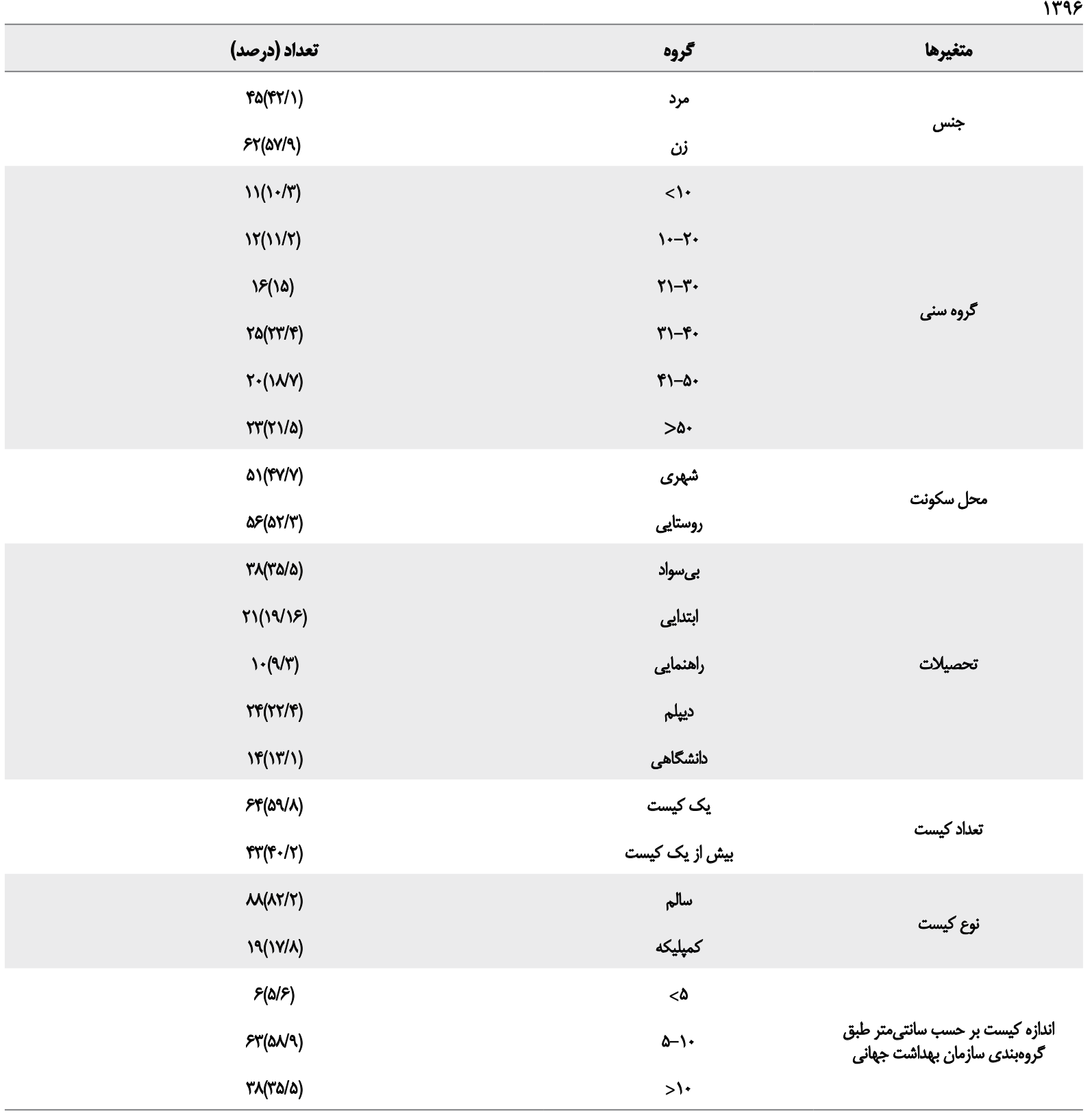

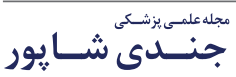

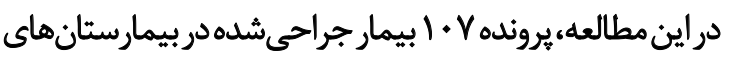

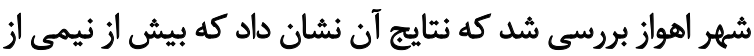

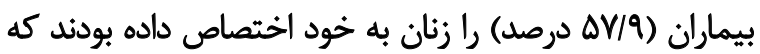

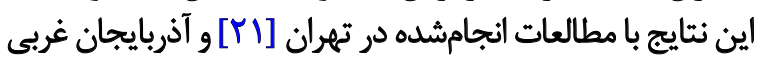

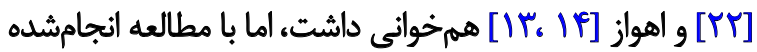

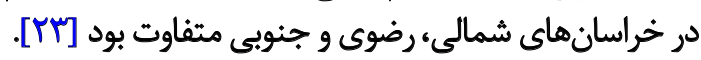
ازجمله عواملى كه در ابتلاى بيشتر زنان مي تواند مؤثر باشد،

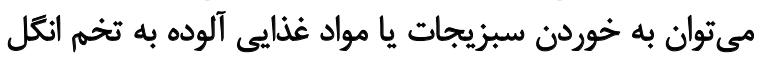

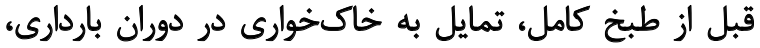

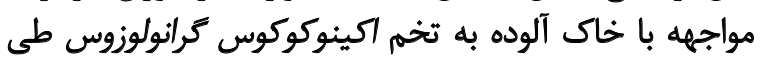

غذا از سوى سازمان خواروبار و كشاورزى ملل متحد (فائو) و

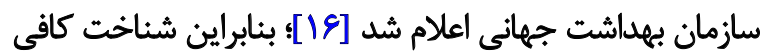

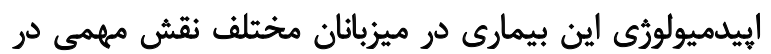
كنترل آن دارد [IV] در ايران شيوع كلى كيست هيداتيد در ميزبانان واسط حيوانى

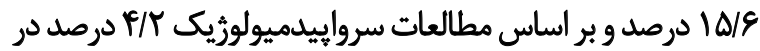

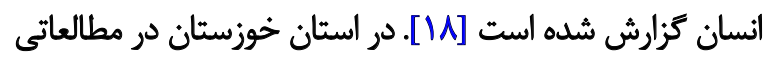

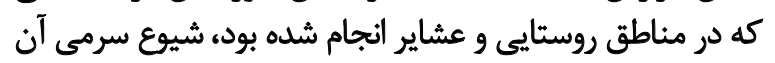

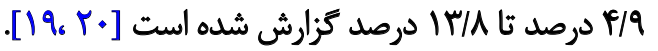




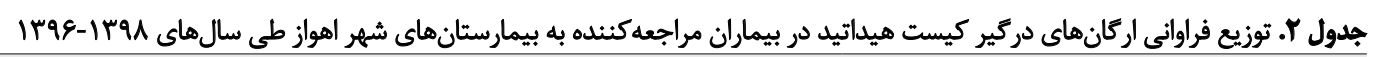

\begin{tabular}{|c|c|}
\hline تعداد (درصد) & اركان دركير \\
\hline$V \Delta(Y-N)$ & كبد \\
\hline $10(19)$ & ريه \\
\hline$V(g / \Delta)$ & كبدوريه \\
\hline$r(1 / 9)$ & كبد وطحال \\
\hline $1(\cdot / 9)$ & كبد، ريه وطحال \\
\hline $1(\cdot / 9)$ & كبلد ورحم \\
\hline$P(T / M)$ & ناغ \\
\hline $1(\cdot / 9)$ & كليه \\
\hline $1(\cdot / 9)$ & شكم \\
\hline
\end{tabular}

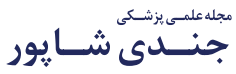

جدول ب . لوب دركير، طبقلبئدى كيست بر اساس كرومبئدى سازمان بهداشت جهانى، روش جراحى و عوارض بعد از عمل در \&A بيمار مبتلابه كيست هيداتيد كبدى

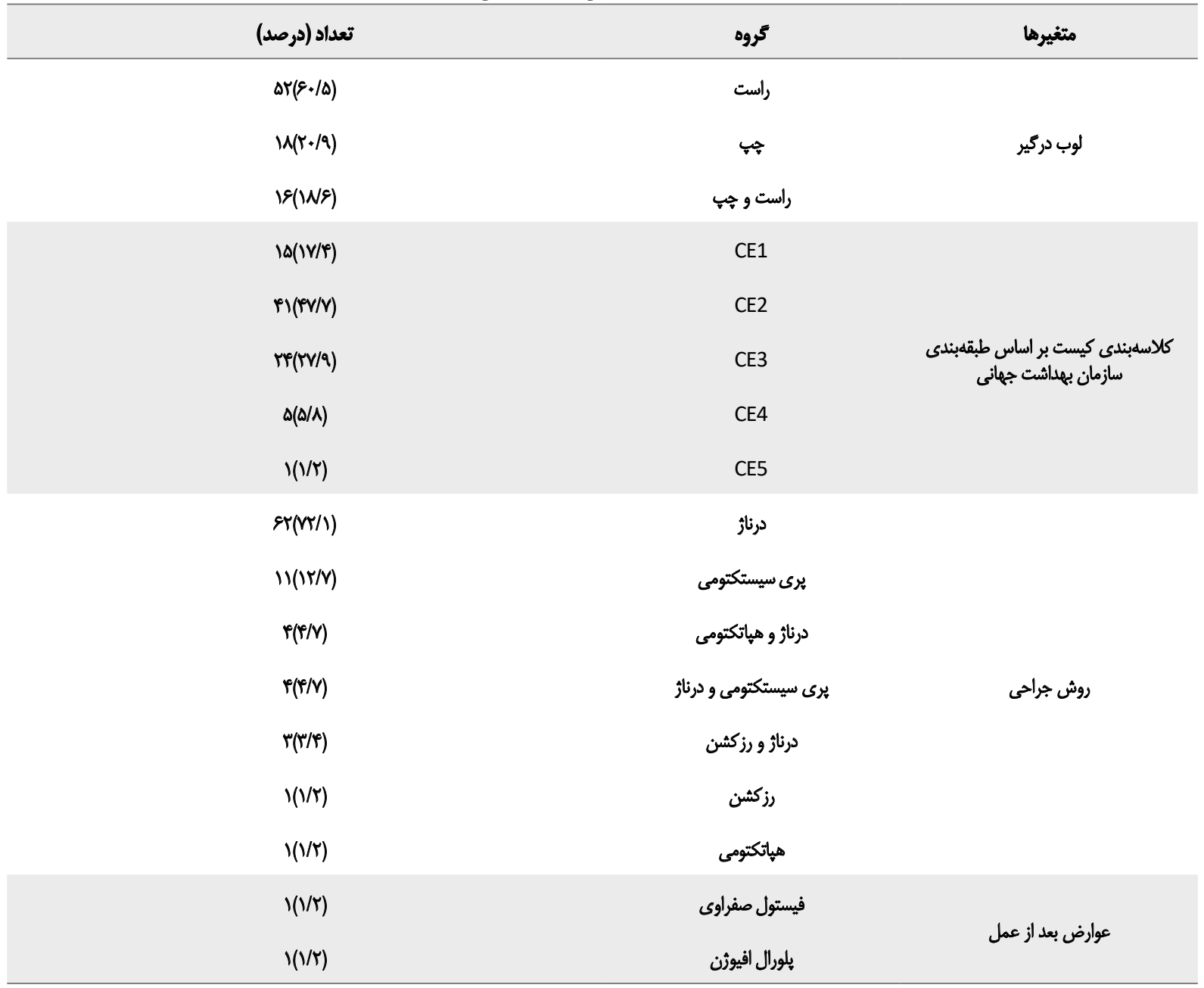

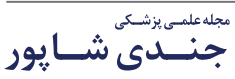




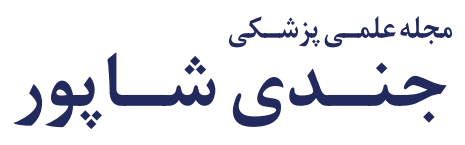

جدول ع. لوب دركير، روش جراحى و عوارض بعد از عمل در TF بيمار مبتلاى كيست هيداتيد ريوى

\begin{tabular}{|c|c|c|}
\hline تعداد (درصد) & 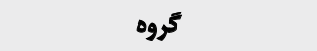 & طبقدبندى \\
\hline$g(T \Delta)$ & لوب تحتانى راست & \multirow{8}{*}{ ل لوب دركير } \\
\hline$\Delta(r+/ \Lambda)$ & لوب فوقانى راست & \\
\hline$r(I r / \Delta)$ & لوب ميانى راست & \\
\hline$\Delta(T+/ \Lambda)$ & لوب تحثانى جِي & \\
\hline$r(N+)$ & لوب فوقائى جي & \\
\hline$l(F / T)$ & لوب تحثانى و فوقانى رالست & \\
\hline$(n / T)$ & لوب تحثانى و فوقانى هيب & \\
\hline$(n / \pi)$ & لوب راست وجيب & \\
\hline$\Delta(r \cdot / A)$ & رزكشن و توراكوتومى & \multirow{5}{*}{ روش جراحى } \\
\hline$F(1 \& M)$ & رزكشن، درناز و توراكوتومى & \\
\hline$\|(F / A)$ & درنازٌ و توراكوتومى & \\
\hline$r(I r / \Delta)$ & ج رزكشن وتوراكوتومى & \\
\hline$(s / \%)$ & كاييتوناز و توراكوتومى & \\
\hline$(F / T)$ & أمييم & \multirow{4}{*}{ عوارض بعلد از عمل } \\
\hline$r(N)^{N}$ & ينوموتوراكس و هيدروينوموتوراكس & \\
\hline$r(I r / \Delta)$ & يلورال افيوثن & \\
\hline$r(1 r / Q)$ & فيستول برونكويلورال & \\
\hline
\end{tabular}

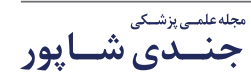

داشت، اما با مطالعه انجامشده در شمال ايران متفاوت بود [YA].

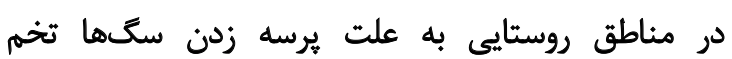

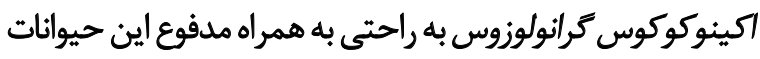

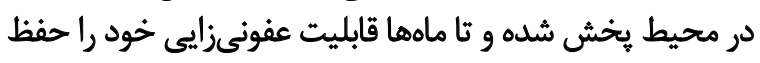

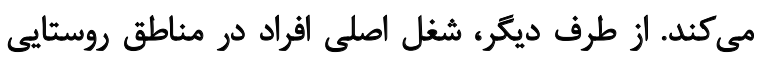

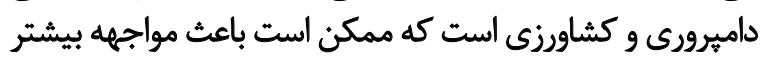

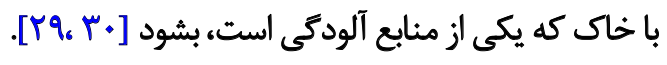

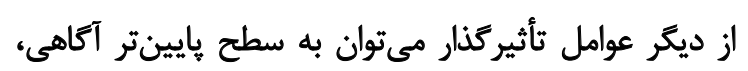

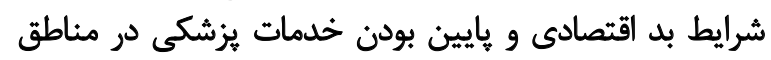

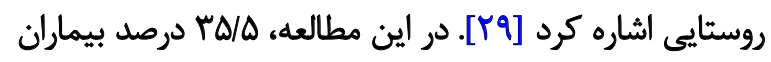

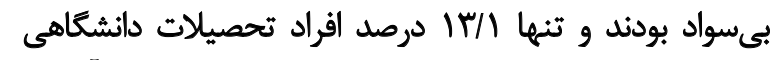

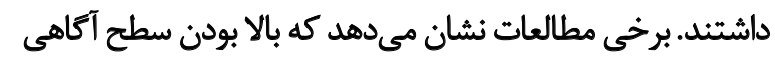

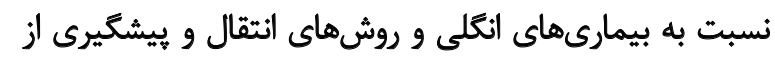

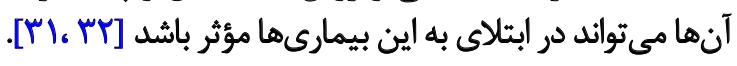

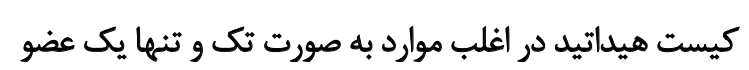

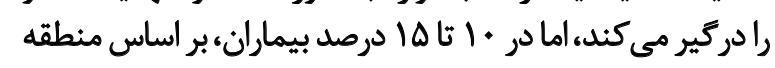

فعاليتهاى روزمره نظير خانهدارى، كشاورزى و داميرورىى، تماس

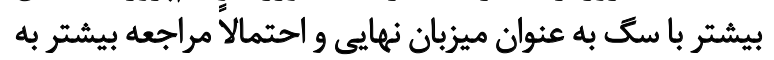

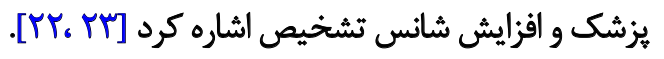

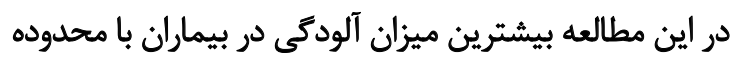

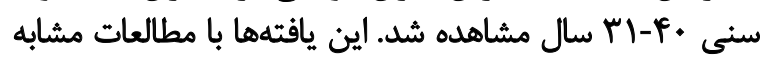

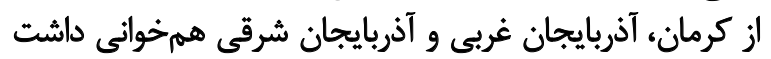

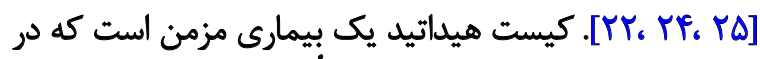

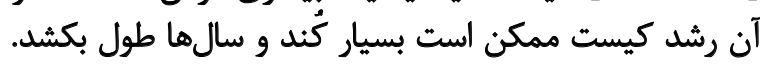

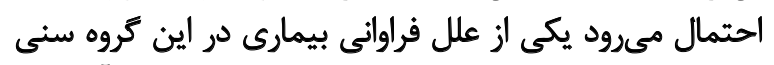

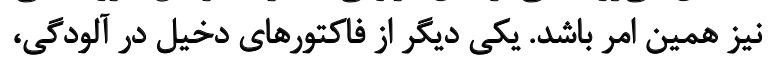

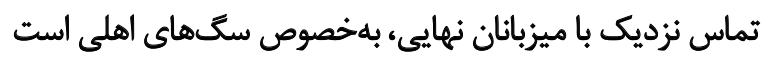

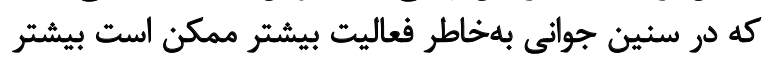

اتفاق بيفتد [11]

نثايج اين بررسى نشان داد كه ميزان آلودكى در افراد ساكن

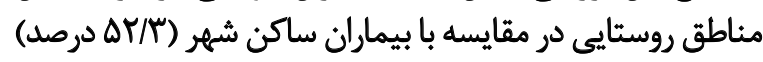

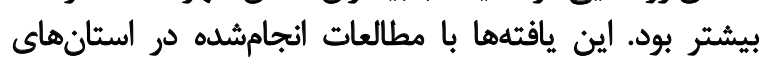

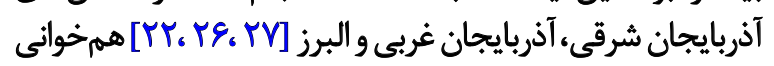




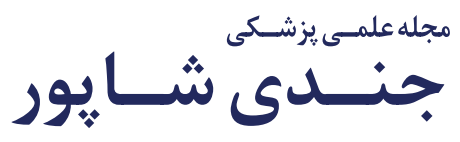

\begin{tabular}{|c|c|c|}
\hline \multicolumn{3}{|c|}{ جدول ه. علائم بالينى در بيماران مبتلا به كيست هيداتيد بر اساس اركمانهاى دركير } \\
\hline مرصد & محل كيست (موارد علامتدار / مجموع مبثلايان همان عضو) & علائهم بالينى \\
\hline $\mathrm{rq} / \mathrm{\Delta}$ & 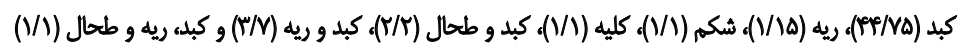 & 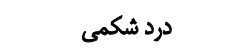 \\
\hline 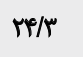 & كبد (Tه/NQ) وكبد وريه (I/M) & درد ريع فوقانى راست شكم \\
\hline$V / \Delta$ & 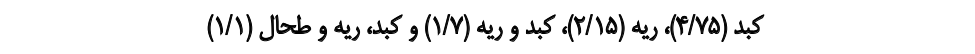 & مرد ربع فوقانى جيب شكم. \\
\hline $\mid r /$ & كبد (II/NQ)، كبد و رحم/(V/I) و كبد، ريه وطحال (I/I) & درد ايع كاستر \\
\hline $\mathcal{N}$ & كبد (NVA) و شكم/(V/) & احساس توده در شكم \\
\hline$r / A$ & كبد (r/Va) & هياتومكالى \\
\hline$r / N$ & كيد (No) & ز ز زديى \\
\hline .19 & كبد (1/Va) & بانكراتيت \\
\hline $1 / 9$ & كبد (T/NO) & فشار خون يوردال \\
\hline$r / Y$ & كبد (T/NQ)، ريه (T//D) وكبد ورحم/(M/) & 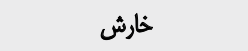 \\
\hline $\mathrm{T} / \mathrm{A}$ & كبد (W/NA) & أسيت \\
\hline$F / N$ & كبد (F/NQ) و كبد وريه (I/N) & 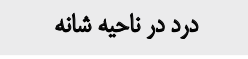 \\
\hline$F / N$ & كبد (ه/VQ) & ا درد منتشره \\
\hline if & 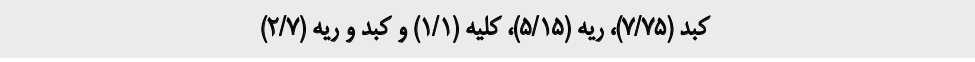 & ت تب ولرز \\
\hline IV/A & 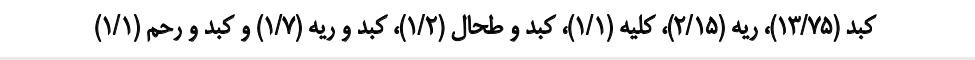 & تק \\
\hline 198 & كبد (1ه/VQ)، ريه (W//D)، كبد و ريه (V/V) و كبد و رحم/(V/I) & 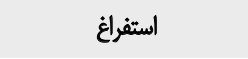 \\
\hline$r / N$ & $(* / p)$ \& ن & كمر درد \\
\hline$\Delta / 8$ & 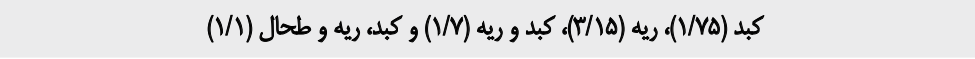 & سرفْه كُشَى \\
\hline $\mid r / 1$ & كبد (INA)، ريه (1/NQ (1) وكبد وريه (T/) & سرفه خلططدار \\
\hline if & كبد (T/Nه)، ريه (N/N/ه) كبد و ريه (T/N) وكبد، ريه و طحال (M) & ت تيكى نفس \\
\hline$\Delta / 8$ & 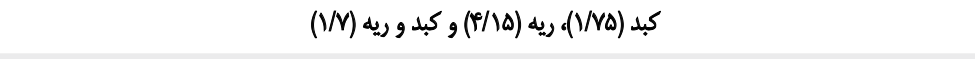 & درد در قفسه سينه \\
\hline$V / \Delta$ & ريه (M/IQ) و كبدو ريه (M/) & خلط خونى \\
\hline $1 / 9$ & كبد (I/VQ) و كبد وريه (M/ & 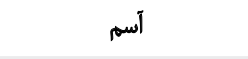 \\
\hline $1 / 9$ & كبد & قاقد علاثم بالينى \\
\hline
\end{tabular}

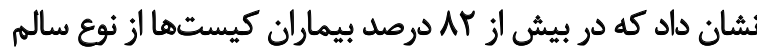

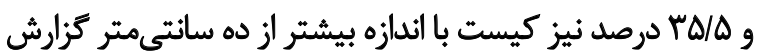
شده بود.

كبد و ريهها از شايعترين اركانهاى دركير در بيمارى

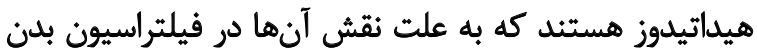

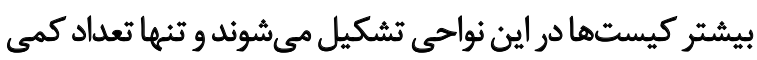

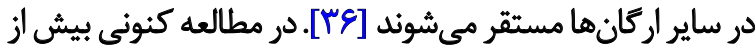

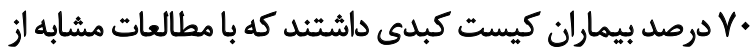

خاص جغرافيايى و استرين انكل ممكن است بيش از يك عضو

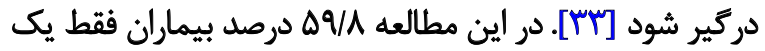

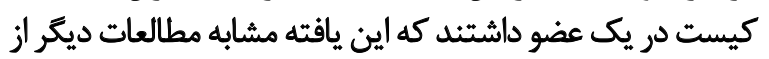

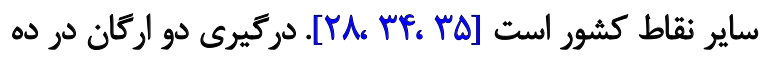

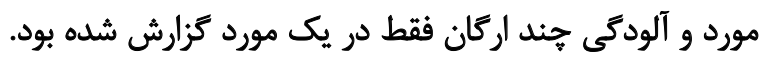

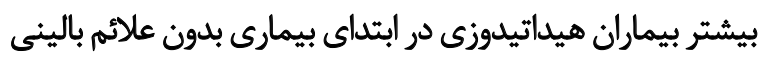

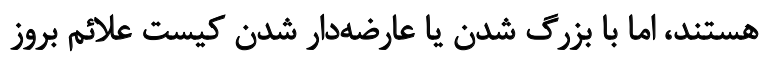

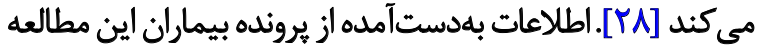




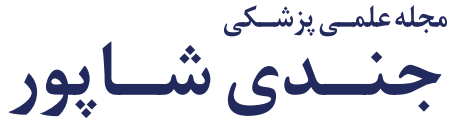

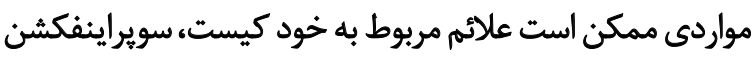

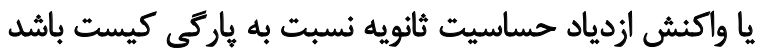

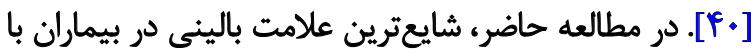

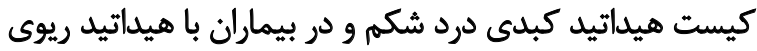

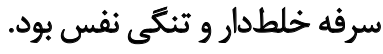
در مطالعه الجوابره و همكاران در فلسطين، درد شكم در اثري

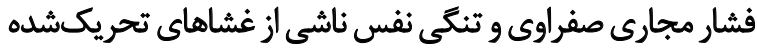

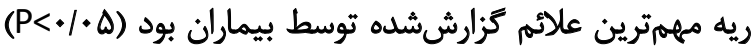

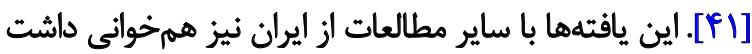

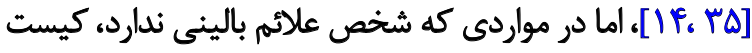

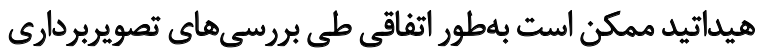

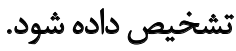

اولتراسوند در تشخيص، تعيين مراحل رشد كيست و ييكيرى دئي

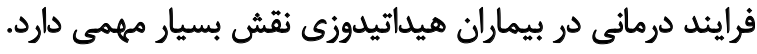

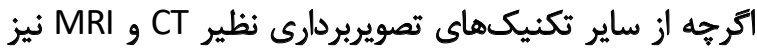

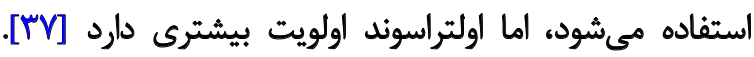

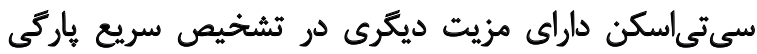

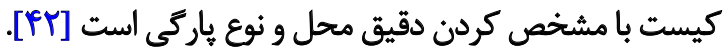

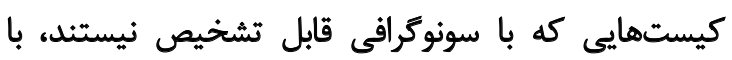

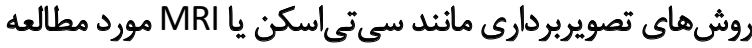

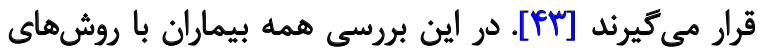

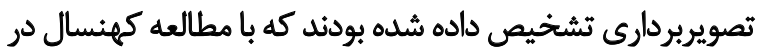

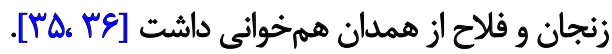

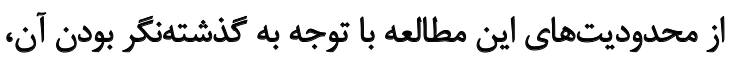

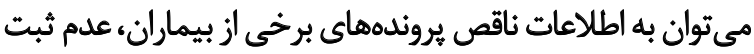

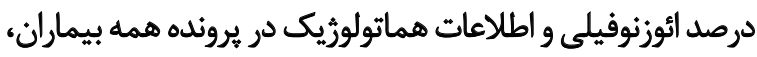

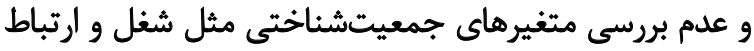
آنها با كيست هيداثيد اشاره كرد.

\section{نتيجليرى}

نتايج اين بررسى نشان داد كه كيست هيداتيد در استان

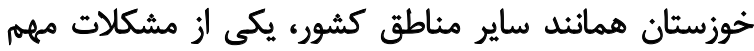

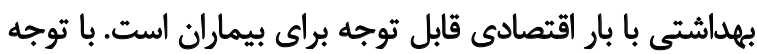

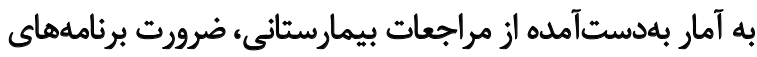

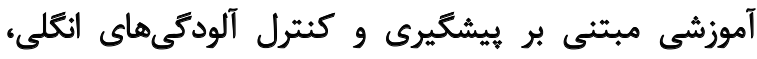

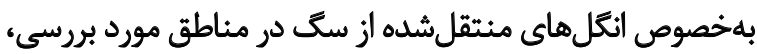

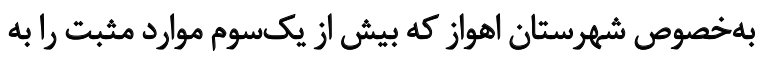
خود اختصاص داده بود، مطرح مىشودان

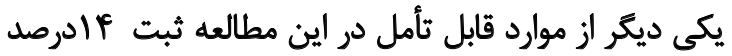

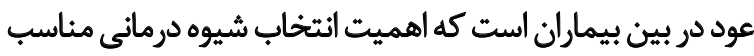

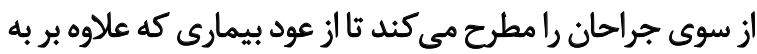
خطر انداختن جان بيمار، بار اقتصادى فراوانى براى بيمار به همراه بـاه
ساير مناطق كشور همخوانى داشت [YY. YY، YV، TL]

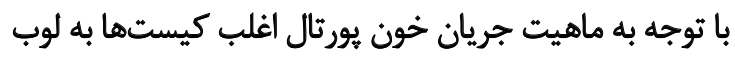

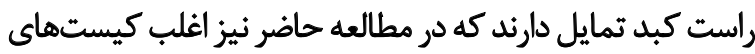

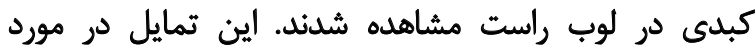

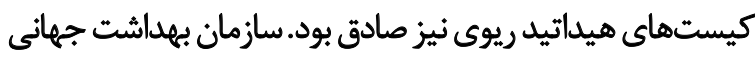

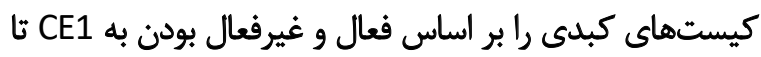

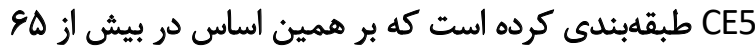

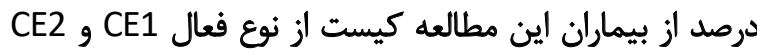

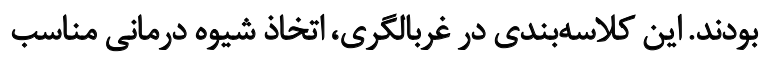
و فالوآب بيماران اهميت زيادى داريندي داردي

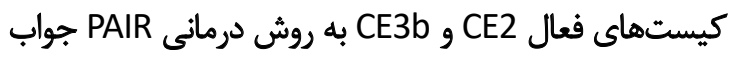

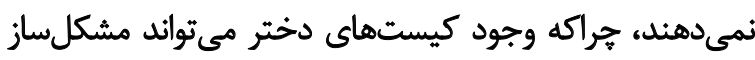

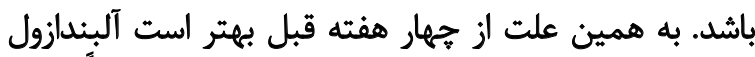

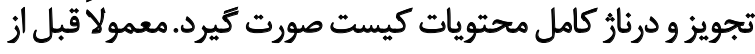

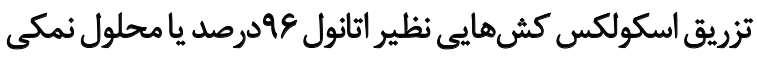

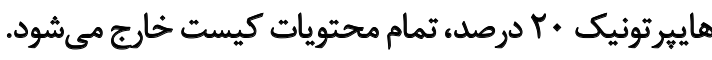

كا CE4 و CE5 ويز كيست در حال كلسيفيه شدن يا اينكه

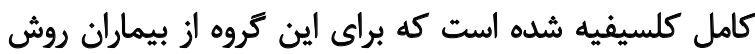

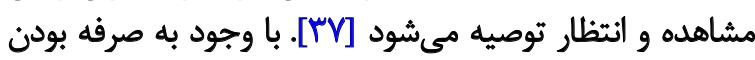

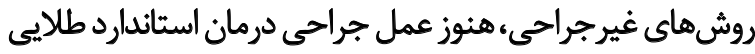

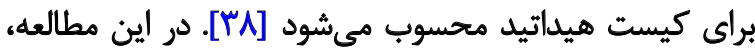

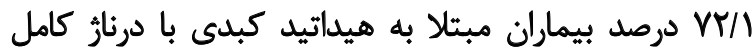

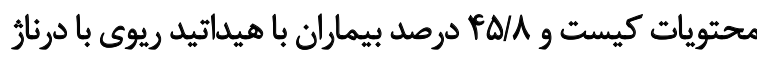
و توراكوتومى درمان شده بودند كه با مطالعات مشابه همرخواني درئي

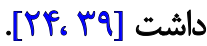

ميزان ياركى كيست هنغام عمل جراحى يازده مورد كزارش

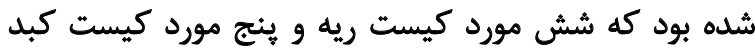

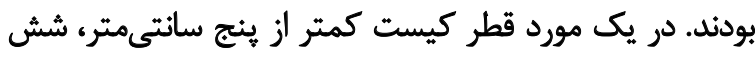

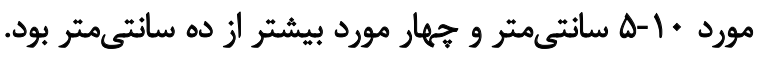

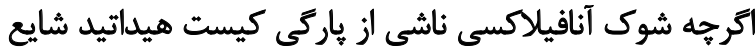

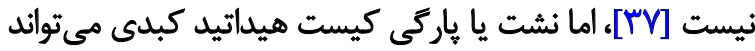

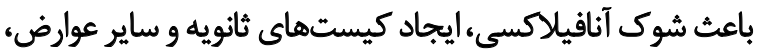

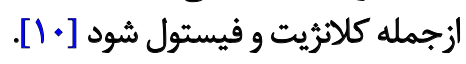

در اين مطالعه علاوه بر fادرصد عود بيماري، يك مورد يلادورد

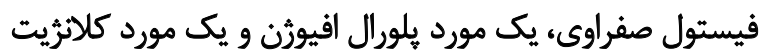

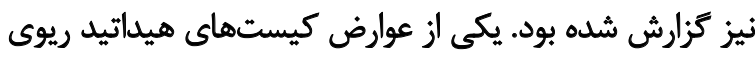

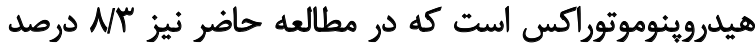

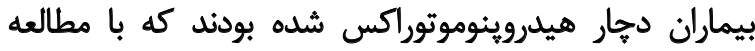

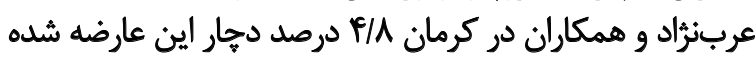

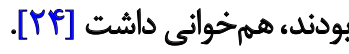

در بيماران مبتلا به كيست هيداتيد ممكن است علائم بالينى فينى اختصاصى نباشد يا اينكه فرد فاقد علائم بالينى باشده، اما در 
دارد، جلو كيرى شود.

مالاحظات اخلاقى

بيروى أز الصول الخالاق هُؤهش

روش اجراي اين مطالعه توسط كميته اخلاق دانشكاه

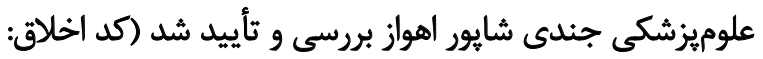

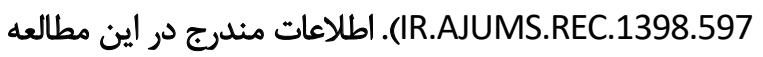
با رعايت شرايط محرمانتى از نوع كذشتهنكر و با مراجعه به ايه

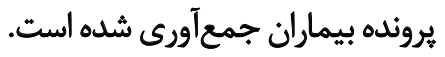

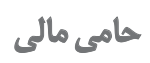

هزينهاى براى انجام اين مطالعه از هيجيج نهاد، سازمان و يا دانشكاهى دريافت نشده است.

$$
\text { مشاركت نويسندكان }
$$

مفهومسازى: ملوك بيرموند، عبدالله رفيعى؛ تحقيق و بررسي:

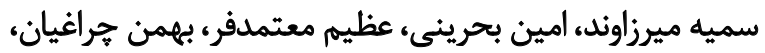

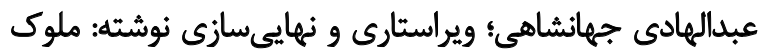
بيرم وند، عبدالله رفيعى، سميه ميرزاوند

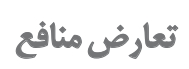

بنابر اظهار نويسندكان اين مقاله تعارض منافع ندارد.

$$
\text { تشكر و قدردائى }
$$

از يرسنل محترم بخش مدارك يزشكى بيمارستانهاى شهر

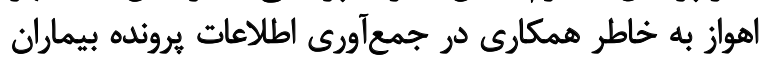

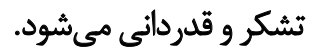




\section{Refrences}

[1] Siracusano A, Delunardo F, Teggi A, Ortona E. Host-parasite relationship in cystic echinococcosis: An evolving story. Clin Dev Immunol. 2012; 2012:639362. [DOI:10.1155/2012/639362] [PMID] [PMCID]

[2] Zhang C, Wang L, Ali T, Li L, Bi X, Wang J, et al. Hydatid cyst fluid promotes peri-cystic fibrosis in cystic echinococcosis by suppressing miR-19 expression. Parasit Vectors. 2016; 9(1):278. [DOI:10.1186/s13071-016-1562-x] [PMID] [PMCID]

[3] WHO. Investing to overcome the global impact of neglected tropical diseases: Third WHO report on neglected tropical diseases 2015. Geneva: World Health Organization; 2015. http://apps.who.int/iris/bitstream/handle/10665/152781/9789241564861_eng.pdf?sequence=1

[4] Cardona GA, Carmena D. A review of the global prevalence, molecular epidemiology and economics of cystic echinococcosis in production animals. Vet Parasitol. 2013; 192(1-3):10-32. [DOI:10.1016/j.vetpar.2012.09.027] [PMID]

[5] Siracusano A, Delunardo F, Teggi A, Ortona E. Cystic echinococcosis: Aspects of immune response, immunopathogenesis and immune evasion from the human host. Endocr Metab Immune Disord Drug Targets. 2012; 12(1):16-23. [DOI:10.2174/1 87153012799279117] [PMID]

[6] WHO Informal Working Group. International classification of ultrasound images in cystic echinococcosis for application in clinical and field epidemiological settings. Acta Trop. 2003; 85(2):253-61. [DOI:10.1016/S0001-706X(02)00223-1]

[7] Moro P, Schantz PM. Echinococcosis: A review. Int J Infect Dis. 2009; 13(2):125-33. [DOI:10.1016/j.ijid.2008.03.037] [PMID]

[8] Santivanez S, Garcia HH. Pulmonary cystic echinococcosis. Curr Opin Pulm Med. 2010; 16(3):257-61. [DOI:10.1097/ MCP.0b013e3283386282] [PMID] [PMCID]

[9] Derbel F, Mabrouk MB, Hamida MBH, Mazhoud J, Youssef S, Ali $A B$, et al. Hydatid cysts of the liver-diagnosis, complications and treatment. In: Derbel F, editor. Abdominal Surgery. London: IntechOpen; 2012. https://books.google.com/books/ about/Abdominal_Surgery.html?id=x6nJzgEACAAJ

[10] McManus DP, Gray DJ, Zhang W, Yang Y. Diagnosis, treatment, and management of echinococcosis. BMJ. 2012; 344:e3866. [DOI:10.1136/bmj.e3866] [PMID]

[11] Rokni M. [Echinococcosis/hydatidosis in Iran (Persian)]. Iran J Parasitol. 2009; 4(2):1-16. https://www.sid.ir/en/journal/ ViewPaper.aspx?id=141776

[12] Fasihi Harandi M, Budke CM, Rostami S. The monetary burden of cystic echinococcosis in Iran. PLoS Negl Trop Dis. 2012; 6(11):e1915. [DOI:10.1371/journal.pntd.0001915] [PMID] [PMCID]

[13] Saki J, khodkar I, Pasand LH, Nazari I. [An epidemiological study on the status of Hydatid cyst in surgical patients in Golestan Hospital of Ahwaz during 2002-2011 (Persian)]. Iran J Med Microbiol. 2019; 12(6):442-6. https://www.sid.ir/en/ Journal/ViewPaper.aspx?ID=701587
[14] Yad Yad M, Nasiri S, Delavari M, Arbabi M. [Survey of hydatid cyst surgeries in hospitals affiliated to Ahvaz Jundishapur University of Medical Sciences during 2004 to 2014 (Persian)]. Feyz J Kashan Univ Med Sci. 2017; 21(5):477-82. http:// eprints.kaums.ac.ir/3088/

[15] Romig T, Deplazes $P$, Jenkins D, Giraudoux P, Massolo A, Craig PS, et al. Ecology and life cycle patterns of echinococcus species. Adv Parasitol. 2017; 95:213-314. [DOI:10.1016/ bs.apar.2016.11.002] [PMID]

[16] Tamarozzi F, Akhan O, Cretu CM, Vutova K, Fabiani M, Orsten $\mathrm{S}$, et al. Epidemiological factors associated with human cystic echinococcosis: A semi-structured questionnaire from a large population-based ultrasound cross-sectional study in eastern Europe and Turkey. Parasit Vectors. 2019; 12(1):371. [DOI:10.1186/s13071-019-3634-1] [PMID] [PMCID]

[17] Haleem S, Niaz S, Qureshi NA, Ullah R, Alsaid MS, Alqahtani $A S$, et al. Incidence, risk factors, and epidemiology of cystic echinococcosis: A complex socioecological emerging infectious disease in Khyber Pakhtunkhwa, Province of Pakistan. BioMed Res Int. 2018; 2018:5042430. [DOI:10.1155/2018/5042430] [PMID] [PMCID]

[18] Khalkhali HR, Foroutan M, Khademvatan S, Majidiani H, Aryamand $S$, Khezri $P$, et al. Prevalence of cystic echinococcosis in Iran: A systematic review and meta-analysis. J Helminthol. 2018; 92(3):260-8. [DOI:10.1017/S0022149X17000463] [PMID]

[19] Beiromvand M, Rafiei A, Mirzavand S, Rahdar M, Feiz Haddad $\mathrm{MH}$. Screening of cystic echinococcosis and toxocariasis in rural inhabitants of Khuzestan Province, southwest Iran. Trop Biomed. 2018; 35(1):32-40. [PMID]

[20] Rafiei A, Hemadi A, Maraghi S, Kaikhaei B, Craig PS. Human cystic echinococcosis in nomads of south-west Islamic Republic of Iran. East Mediterr Health J. 2007; 13(1):41-8. [PMCID].

[21] Ahmadi N, Bodi F. Clinical presentation, localization and morphology of hepato-pulmonary hydatid cysts in patients operated in Tehran. World Appl Sci J. 2011; 12(9):1544-8. http:// www.idosi.org/wasj/wasj12(9)/27.pdf

[22] Hajipirloo HM, Bozorgomid A, Alinia T, Tappeh KH, Mahmodlou R. Human cystic echinococcosis in west azerbaijan, northwest iran: A retrospective hospital based survey from 2000 to 2009. Iran J Parasitol. 2013; 8(2):323-6. [PMCID]

[23] Ebrahimipour M, Budke CM, Najjari M, Yaghoobi K. Surgically managed human cystic echinococcosis in north-eastern Iran: A single center's experience from 2001 to 2008. J Parasit Dis. 2017; 41(3):883-7. [DOI:10.1007/s12639-017-0911-9] [PMID] [PMCID]

[24] Arabnejad F, Lashkarizadeh MR, Mohseni MM, Lashkarizadeh E, Smareh Fekri M, Ahmadinejad M. [Epidemiology and early complications of lung and liver hydatid cyst surgery among patients referred to Afzalipour Hospital, Kerman University of Medical Sciences during 2003-2013 (Persian)]. J Kerman Univ Med Sci. 2016; 23(5):543-53. https://iranjournals.nlai.ir/handle/123456789/249539 
[25] Vahedi MA, Vahedi ML. Demographics of patients with surgical and nonsurgical cystic echinococcosis in East Azerbaijan from 2001 to 2012. Pak J Biol Sci. 2012; 15(4):186-91. [DOI:10.3923/ pjbs.2012.186.191] [PMID]

[26] Ghabouli Mehrabani N, Kousha A, Khalili M, Mahami Oskouei M, Mohammadzadeh M, Alizadeh S, et al. Hydatid cyst surgeries in patients referred to hospitals in East Azerbaijan Province during 2009-2011. Iranian journal of parasitology. 2014; 9(2):233-8. [DOI:10.17420/ap6604.302].

[27] Omidinia N, Zibaei M, Hosseini H, Pourrostami K, Vafae Eslahi A, Badri M. Human hydatidosis in Alborz Province: A 5-year retrospective epidemiological analysis of hospitalized cases (2014-2019). Ann Parasitol. 2020; 66(4):587-92. doi:10.17420/ ap6604.302. [DOI:10.17420/ap6604.302].

[28] Islami Parkoohi P, Jahani M, Hosseinzadeh F, Taghian S, Rostami F, Mousavi A, et al. Epidemiology and clinical features of hydatid cyst in Northern Iran from 2005 to 2015. Iran J Parasitol. 2018; 13(2):310-6. [PMCID].

[29] Amahmid O, El Guamri Y, Zenjari K, Bouhout S, Moh MA, Boraam $F$, et al. Epidemiology and clinical features of human cystic echinococcosis in adults from an endemic area (Morocco). Clin Epidemiol Glob Health. 2020; 8(2):606-11. [DOI:10.1016/j. cegh.2019.12.011]

[30] Brunetti E, Garcia HH, Junghanss T. Cystic echinococcosis: Chronic, complex, and still neglected. PLoS Negl Trop Dis. 2011; 5(7):e1146. [DOI:10.1371/journal.pntd.0001146] [PMID] [PMCID]

[31] Baghlaninezhad R, Beiromvand M, Veisi MS. Analysis of knowledge and attitudes related to parasitic infections among inhabitants of Ahvaz County, Khuzestan Province, Iran. Acta Trop. 2019; 193:211-6. [DOI:10.1016/j.actatropica.2019.03.014.] [PMID]

[32] Khan A, Naz K, Ahmed H, Simsek S, Afzal MS, Haider W, et al. Knowledge, attitudes and practices related to cystic echinococcosis endemicity in Pakistan. Infect Dis Poverty. 2018; 7(1):4. [DOI:10.1186/s40249-017-0383-2] [PMID] [PMCID]

[33] Pakala T, Molina M, Wu GY. Hepatic echinococcal cysts: A review. J Clin Transl Hepatol. 2016; 4(1):39-46. [DOI:10.14218/ JCTH.2015.00036] [PMID] [PMCID]

[34] Shahriarirad R, Erfani A, Eskandarisani M, Rastegarian $M$, Taghizadeh $H$, Sarkari B. Human cystic echinococcosis in southwest Iran: A 15 -year retrospective epidemiological study of hospitalized cases. Trop Med Health. 2020; 48:49. [DOI:10.1186/ s41182-020-00238-3] [PMID] [PMCID]

[35] Khazaei S, Rezaeian S, Khazaei Z, Goodarzi E, Khazaei S, Mohammadian $\mathrm{M}$, et al. Epidemiological and clinical characteristics of patients with hydatid cysts in Khorasan Razavi province, from 2011 to 2014. Iran J Parasitol. 2016; 11(3):364-70. [PMCID].

[36] Kohansal MH, Nourian A, Bafandeh S. Human cystic echinococcosis in Zanjan Area, Northwest Iran: A retrospective hospital based survey between 2007 and 2013. Iran J Public Health. 2015; 44(9):1277-82. [PMCID]

[37] Brunetti E, Tamarozzi F, Macpherson C, Filice C, Piontek MS, Kabaalioglu A, et al. Ultrasound and cystic echinococcosis. Ultrasound Int Open. 2018; 4(3):E70-8. [DOI:10.1055/a-0650-3807] [PMID] [PMCID]
[38] Zaharie F, Bartos D, Mocan L, Zaharie R, lancu C, Tomus C. Open or laparoscopic treatment for hydatid disease of the liver? A 10year single-institution experience. Surg Endosc. 2013; 27(6):21106. [DOI:10.1007/s00464-012-2719-0] [PMID] [PMCID]

[39] Aghajanzadeh M, Mohammadzadeh M, Safarpour F. [Evacuation and bronchial opening closure (EBOC): Assessment results of 100 surgical cases (Persian)]. J Urmia Univ Med Sci. 2006; 17(1):1-5. https://www.sid.ir/en/journal/ViewPaper. aspx?id=84979

[40] Amado-Diago CA, Gutierrez-Cuadra M, Arminanzas C, Arnaiz de Las Revillas F, Gomez-Fleitas M, Farinas MC. Echinococcosis: A 15-year epidemiological, clinical and outcome overview. Rev Clin Esp. 2015; 215(7):380-4. [DOI:10.1016/j.rce.2015.05.003] [PMID]

[41] Al-Jawabreh A, Ereqat S, Dumaidi K, Nasereddin A, Al-Jawabreh H, Azmi K, et al. The clinical burden of human cystic echinococcosis in Palestine, 2010-2015. PLoS Negl Trop Dis. 2017; 11(7):e0005717. [DOI:10.1371/journal.pntd.0005717] [PMID] [PMCID]

[42] Alexiou K, Mitsos S, Fotopoulos A, Karanikas I, Tavernaraki $\mathrm{K}$, Konstantinidis F, et al. Complications of hydatid cysts of the liver: Spiral computed tomography findings. Gastroenterology Res. 2012; 5(4):139-43. [DOI:10.4021/gr460e] [PMID] [PMCID]

[43] Agudelo Higuita NI, Brunetti E, McCloskey C. Cystic echinococcosis. J Clin Microbiol. 2016; 54(3):518-23. [DOI:10.1128/ JCM.02420-15] [PMID] [PMCID] 